\title{
Chapter 4 \\ The Persistent Influence of Socio-Economic Background on Family Formation Pathways and Disadvantage in Young Adulthood
}

\author{
Jarl Mooyaart
}

\subsection{Introduction}

Starting from the second half of the twentieth century there have been dramatic changes in the family formation pathways in most Western countries (Buchmann and Kriesi 2011; Lesthaeghe 2010; Shanahan 2000). Pathways have become less standard and more diverse, with increases in unmarried cohabitation, childbirth within unmarried couples, and separation and divorce (Brückner and Mayer 2004). These new family behaviors have spread across all social strata (Lesthaeghe 2010). Some suggest that family formation patterns have been increasingly shaped by individual preferences, resulting in a 'choice biography' (Giddens 1991; Woodman 2009). Others claim that there is a diverging pattern in family formation between those of high and low socio-economic class. McLanahan (2004) describes how lower educated women are increasingly likely to become single parents compared with highly educated women in the United States, in what she calls "Diverging Destinies". Perelli-Harris and colleagues (Perelli-Harris and Gerber 2011; PerelliHarris et al. 2010) argue that many family behaviors in Europe are not the result of individual choice, but of structural constraints, and they describe for instance the increasing rate of childbearing within cohabitation rather than marriage as a result of a "Pattern of Disadvantage". Thus, there is some debate to what extent the new diverse set of family formation patterns are the result of cultural changes in individual preferences or the result of changes in structural conditions.

In this chapter I will focus on the influence of socio-economic background on family formation behavior and disadvantage in young adulthood, drawing on results

\footnotetext{
J. Mooyaart $(\square)$

Netherlands Interdisciplinary Demographic Institute (NIDI), The Hague, The Netherlands

University of Groningen, Groningen, The Netherlands

e-mail: mooyaart@ nidi.nl
} 
of my dissertation titled "Linkages between family background, family formation and disadvantage in young adulthood" (Mooyaart 2019). The first question I address in this chapter is: To what extent has the influence of socio-economic background on family formation changed over time? I will offer answers to this question in two ways. First, I will report on changes over time in the link between parental education and the timing of the first union, the timing of first marriage and the choice of marriage versus cohabitation, using survey data from the Netherlands. Whereas some previous studies examined the association between parental socio-economic status and family formation over time, they focused predominantly on single transitions (marriage or first union) (South 2001; Wiik 2009). However, as these studies have been conducted in countries with relatively different transition patterns (US and Norway) it remained unclear whether their results are generalizable to other countries as well. My study extends the pool of countries on which these relationships are studied by examining changes over time in the link between parental education and timing of first union and first marriage in the Netherlands. My study uniquely advances knowledge on aspects related to the choice of marriage versus cohabitation (Mooyaart and Liefbroer 2016). Second, I will report on a crossnational study that I conducted in which the influence of parental education on the family formation process across countries is examined. Such a direct comparison is provided for four distinct European countries: France, Sweden, Romania and Italy. The novelty of my approach is that it focusses on family formation pathways as an outcome rather than on single outcomes (e.g. marriage and cohabitation separately). With such an approach, the family formation process is viewed from a holistic perspective, acknowledging a key point from the life-course framework, which is that life-course transitions are embedded in trajectories which provide them with a specific meaning (Elder Jr 1994). In order to examine family formation as a process, demographers have increasingly used sequence analysis to capture differences in type, timing and ordering of family transitions (e.g. Aassve et al. 2007; Elzinga and Liefbroer 2007; Zimmermann and Konietzka 2017). In this chapter I will use results from a study that combines sequence analysis and event-history analysis.

While socio-economic background sets the stage for how youths make the transition into adulthood, the second question I will address in this chapter is: Does socioeconomic background continue to play an influential role throughout young adulthood regarding aspects related to family formation and socio-economic position? I will report on three sets of research findings that provide valuable answers to this question. First, I will discuss how the association between parental education and union formation changes with age (over the young adult period). Moreover, I will examine whether the influence of parental education on the timing of marriage changes when someone enters a cohabiting union. Next, I will discuss to what extent socio-economic disadvantage continues to affect one's own socio-economic position beyond the life-course transitions that the individual makes in young adulthood. In particular, I will illustrate the link between family background, career and family transitions between the age 17 to 25 and personal income trajectories between 25 and 32, using panel data from the United States. I will specifically focus on the extent to which the influence of socio-economic background on personal income 
would persist even if there were no differences between individuals in their career and family pathways up to age 25 . While there is ample research on the intergenerational transmission of disadvantage, its focus has been mainly on the transmission of advantage through educational attainment of the individual (e.g., Blau and Duncan 1967; Blossfeld and Shavit 1993; Breen and Goldthorpe 1997). My findings strongly suggest that a more holistic life-course approach, examining the role of both career and family pathways, can improve our understanding on the intergenerational transmission of (dis)advantage.

\subsection{Socio-Economic Background and Family Formation Over Time}

An important societal change has been the growing social acceptance of unmarried cohabitation. Whereas living with a partner outside marriage was once not done, it has become an accepted phenomenon in most Western countries (Kiernan 2004). Some couples first cohabit before they get married, while other couples never get married. Nowadays, in many Western countries (including the Netherlands), most couples cohabit before they marry, but at the same time most people do eventually marry rather than forego marriage. However, for many in older birth cohorts, unmarried cohabitation with a partner was not considered an option. Lesthaeghe and Van de Kaa (1986) claim that many (Western) countries have gone through the so called Second Demographic Transition (SDT). Changes related to the SDT include the earlier mentioned social acceptance of unmarried cohabitation, but also the postponement of marriage/unions, decline of fertility and postponement of childbearing, and the increasing divorce rate. According to the SDT theory, the changes in demographic behaviors (in the Netherlands starting around the 1960s) occurred because increasing welfare allowed individuals to live more individualistically, less reliant on their social surroundings, as the state would provide its citizens in their basic needs. According to the SDT, the elite social classes were the frontrunners of this social change. The changes described above would, according to the theory, start among the higher classes and then diffuse across all social classes as these behaviors would become increasingly accepted. Thus, new behaviors such as unmarried cohabitation (before or as an alternative to marriage) would first be popular among high social classes and later diffuse among all social classes.

To examine this issue, I focused on the influence of parental socio-economic status (measured by parental education) on union formation, changes over time and across the life-course. One aspect receiving considerable attention in the empirical literature has been the timing of union formation. There is ample research that indicates that children of higher educated parents tend to form unions later than children of lower educated parents (Axinn and Thornton 1992; Cavanagh 2011; Mulder et al. 2006). Several reasons are given in the literature mostly linked with socialization and resources. First, children with highly educated parents are more likely to attend 
higher education themselves (both as a result of resources and socialization) and people that are enrolled in education are less likely to form unions, particularly marriage (Thornton et al. 1995). Second, although wealthy highly educated parents may be able to provide the resources to marry (Avery et al. 1992), the youths themselves may be reluctant to leave the parental home and start a cohabiting union, when it means having to give up on the luxurious life-style that they are used to in the parental home (Easterlin 1980). Finally, highly educated parents are more likely to have started their first unions relatively late in life and therefore their children may postpone union formation themselves as well (Thornton 1991). To examine this issue, I studied the influence of parental education on the timing of the first union, timing of first marriage and the choice for either unmarried or married cohabitation as the first union among Dutch born between 1930 and 1990 (Mooyaart and Liefbroer 2016).

If we have a close look at the existing literature, we notice that only few studies analyzed changes in the influence of parental education on union formation over time and across the life-course (Wiik 2009; South 2001). The results from these studies are somewhat in line with the SDT theory as these studies find that the influence of parental background decreases over time. My study has been the first to analyze the change in the influence of parental education in the Netherlands and also over a long time period, which covers birth cohorts born both before and after the demographic changes associated with the SDT started. Furthermore, another feature of this study is that it takes into account fluctuations in the economy, in order to examine to what extent change in union formation patterns may be the result of economic changes rather than cultural change as predicted by the SDT.

The most surprising result of my study is that the influence of parental education on union formation remains rather stable across birth cohorts. Figure 4.1 shows the interaction between parental education and birth cohort on timing of first union and first marriage separately for men and women. The figure shows negative coefficients of parental education for the 1931 birth cohort, indicating that young adults with higher educated parents are more likely to postpone cohabitation and marriage compared with those with lower educated parents. This most strongly applies for marriage and in particular for young adult men. As the expectation is that differences in parental education will have a weaker influence on cohabitation and marriage timing in younger cohorts, one would expect that the lines gradually approach the $\mathrm{x}$-axis line, indicating a decrease in effect size. However, contrary to expectations the lines do not approximate zero with every increasing birth cohort. Instead the lines are rather flat indicating that the effects for the 1931 cohort are about the same as those for the other birth cohorts. Other results in this study reveal that regarding the choice for marriage or cohabitation as a first union, only for men a decreasing impact of parental education over birth cohort is found. Furthermore, economic circumstances have little impact on the relationship between parental education and union formation as the study finds no significant effect for the interaction between parental education and yearly national economic circumstances. Thus, the influence of parental social class through mechanisms described above remains important. This challenges the idea that societies such as the Netherlands have individualized to the extent that family and institutions no longer influence the 


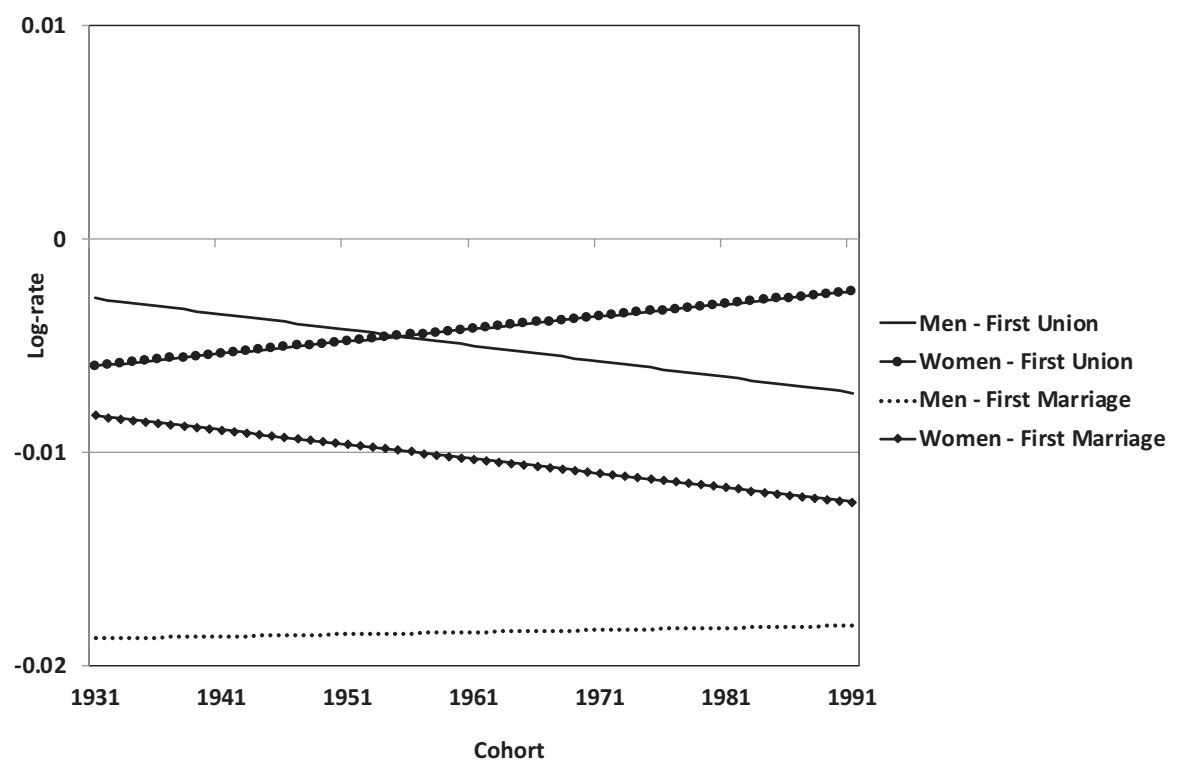

Fig. 4.1 Parameter estimates of the effect of parental education on first union and marriage rates by birth cohort

decision-making of young adults. This contradicts the idea of the SDT that lifecourses would become less stratified.

Although this study showed cohort changes in the influence of parental education on union formation, the research only covers one national context, the Netherlands. In another study reported in Mooyaart (2019), I took a cross-national perspective and compared four national contexts (France, Sweden, Romania and Italy). In this study, family formation is examined as a whole, including both union formation and entry into parenthood. Parental education is again measured as the highest educational level of both parents, dividing parental education into three groups, low, middle and high educated. The goal was to observe to what extent the process of the SDT is visible among all four countries. According to the SDT theory one would expect that in all countries new family formation pathways, i.e. family pathways that diverge from the "traditional" marriage and having children, first appear in the older birth cohorts among those with higher educated parents, and that these new family behaviors will only become more widespread among those of all socio-economic backgrounds in younger birth cohorts. However, given that the SDT occurred two to three decades later in Southern and Eastern Europe than in Northern and Western Europe (Lesthaeghe 2010), one would expect this transition to have occurred earlier in France and Sweden than in Italy and Romania.

This study uses Competing Trajectories Analysis - CTA (Studer et al. 2018), combining sequence analysis with event-history analysis. Following the CTA procedure, sequences are constructed based on the first 6 years after young adults have entered their family formation pathway (either by entering a cohabiting relationship 
or by becoming a parent). In the second step of the procedure sequences are clustered in a typology of family formation pathways. Finally, we conduct event-history analysis, and present its results in graphs showing predicted cumulative entry into the different family formation pathways at age 30 .

The most optimal number of clusters is seven, based on cluster quality statistics (Mooyaart 2019). Here, I briefly describe the different clusters, in decreasing order of popularity across countries and cohorts:

- marriage and parenthood (43.9\%). In this cluster the vast majority marries directly and has a child within 2 years after marrying.

- slow marriage and parenthood (19.6\%). In this cluster one enters family formation through direct marriage or unmarried cohabitation and after 6 years almost all have entered marriage and parenthood.

- cohabitation (12.3\%). Everyone starts with entering unmarried cohabitation and stay in this state for 3-6 years, after which some dissolve their union, some marry and some enter parenthood.

- marriage (9.7\%). This cluster is characterized by the vast majority directly entering marriage and staying in this state for (at least) 6 years.

- cohabitation and parenthood (7.0\%). In this cluster one starts by entering unmarried cohabitation, which is followed by parenthood. A minority in this cluster also marry after about 3 years.

- single parent (4.2\%), This cluster is characterized by entering parenthood without entering a union and being in this state mostly for 6 years.

- cohabitation dissolution (3.3\%) In this cluster one starts with entering unmarried cohabitation, in which this union dissolves within 3 years. Some then enter a new union (mostly unmarried cohabitation).

While this study covers four country contexts, I focus in this chapter on two countries, France (a country experiencing the SDT relatively early) and Romania (a country experiencing the SDT relatively late), to illustrate the influence of parental education over time. Figure 4.2 shows the predicted cumulative entry into the different family formation types at age 30 for France. The results are shown separately for those with high and low educated parents. The two bars on the left side contain the predicted cumulative entry at age 30 into the different family formation types for the oldest birth cohort (1925-1944) and the two bars on the right those for the youngest birth cohort in this study (1965-1990). Results add up to $100 \%$, as we also display those who have not entered family formation or have been censored at timing of interview (for more details see Mooyaart (2019)). In the oldest French cohort (1925-1944), the dominant family formation pathway was marriage and parenthood. Although only few enter into pathways that contain long spells of unmarried cohabitation, this is somewhat more common among young adults with highly educated parents, whereas young adults with low educated parents hardly enter into these pathways at all. This result is in line with predictions from the SDT theory, i.e. those from higher educated background are more likely to initiate these new types of family formation pathways. The bars on the right side show a dramatic shift in the landscape of family formation in France among the 1965-1990 cohort, when 


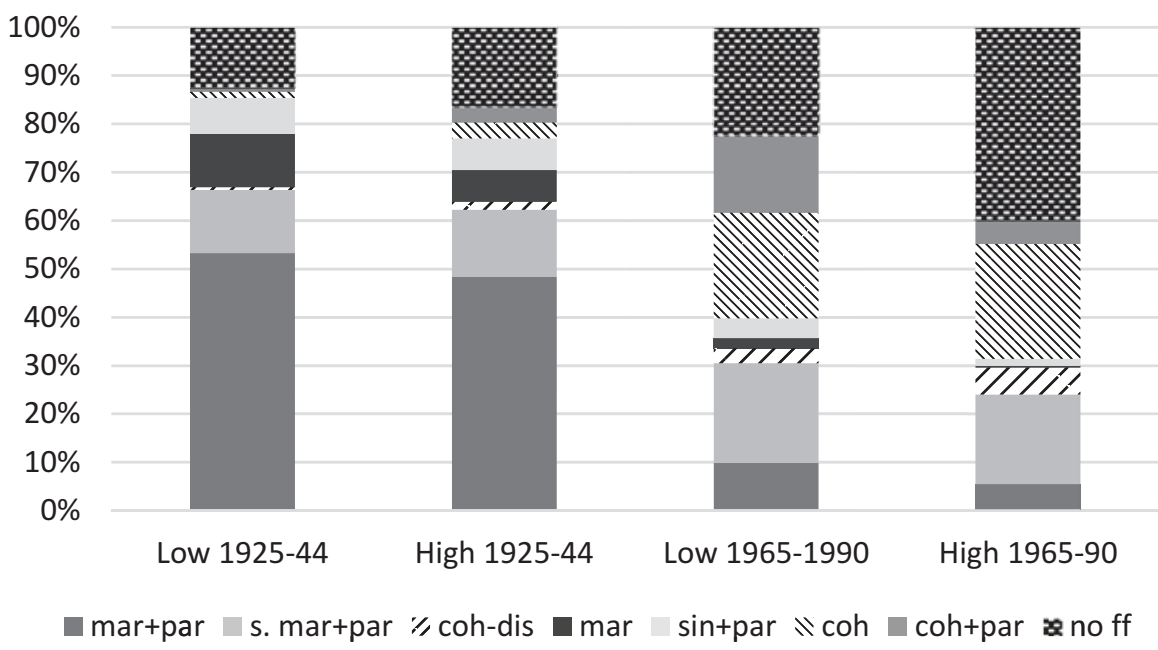

Fig. 4.2 Predicted cumulative entry into family formation types at age 30 by birth cohort and parental educational level in France

Note: mar+par marriage and parenthood, s. mar+par slow marriage and parenthood, coh-dis cohabitation dissolution, mar marriage, sin+par single parenthood, coh cohabitation, coh+par cohabitation and parenthood, no ff no family formation pathway entered/censored

compared with the 1925-1944 cohort. Marriage and parenthood is no longer the dominant family formation pathway, and pathways with cohabitation are becoming more common. Yet, differences remain between those with high and low educated parents. In fact, the differences appear to be stronger in this cohort compared to the older cohort, which is in contrast to what the SDT theory would predict. In the youngest cohort, those with low educated parents are relatively more likely to follow the more "traditional" family formation pathway, i.e. the marriage, marriage and parenthood and slow marriage and parenthood pathways compared with their peers with highly educated parents. They are also more likely to enter the cohabitation and parenthood and single parenthood pathways. Those with high educated parents, on the other hand, generally enter family formation later and more often enter a cohabiting union that dissolves later.

Figure 4.3 displays the results for Romania. Here one can observe less of change in family formation patterns between the cohorts. However, in both cohorts, differences between those with high and low educated parents are visible. In the 1925-1944 birth cohort those with high educated parents show a relatively lower entry into marriage and parenthood, while having a higher entry into the marriage pathway. Moreover, a small proportion enters into the cohabitation pathway, which is hardly present among those with low educated parents. In the 1965-1990 cohort fewer have entered a family formation pathway before age 30, particularly those with highly educated parents. The marriage and parenthood pathway is still clearly dominant among those with low educated parents, yet they also enter the cohabitation and parenthood pathway more often compared to those with highly educated parents. 


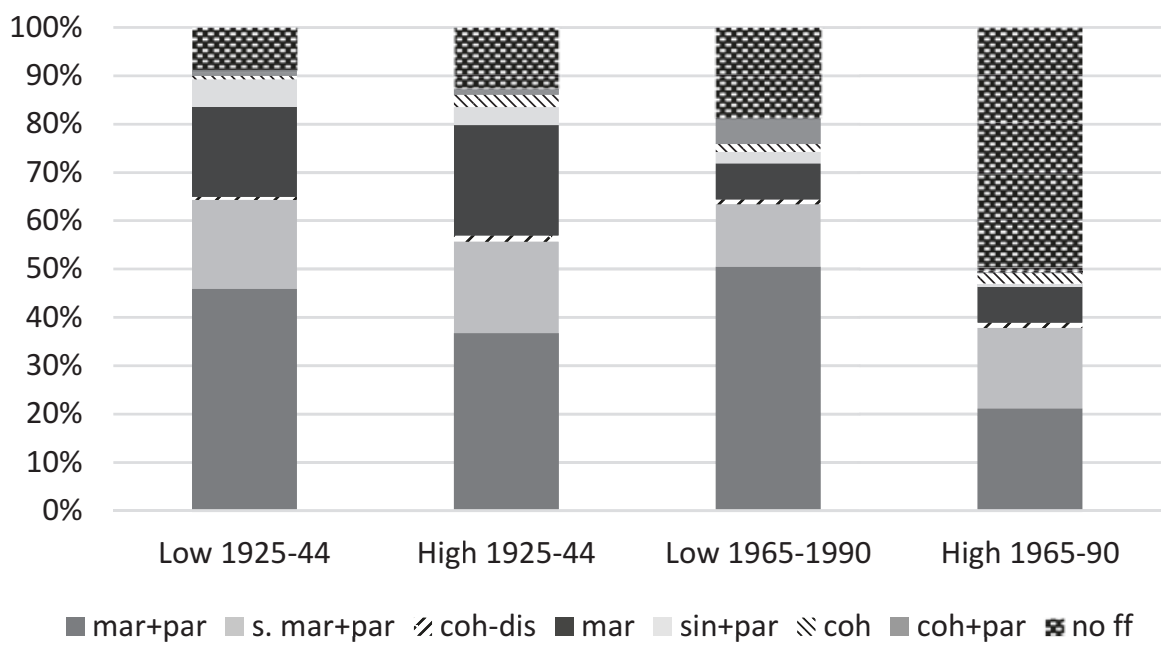

Fig. 4.3 Predicted cumulative entry into family formation types at age 30 by birth cohort and parental educational level in Romania

Note: mar+par marriage and parenthood, s. mar+par slow marriage and parenthood, coh-dis cohabitation dissolution, mar marriage, sin+par single parenthood, coh cohabitation, coh+par cohabitation and parenthood, no ff no family formation pathway entered/censored

Generally, among children of higher educated parents the chance is higher that they opt for a more reversible family formation pathway, i.e. cohabitation dissolution and cohabitation, or even postpone family formation altogether. Children of low educated parents have remained to be more likely to opt for more "traditional" types of pathways and for the family pathways that are more associated with disadvantage, i.e. single parenthood and cohabitation and parenthood. Thus, in line with the first study discussed above there remains a visible impact of parental education that continues to divide individuals in the type of family formation pathways they follow. One could even argue that in the time period covered by this data, divergence occurred.

\subsection{The Influence of Socio-economic Background Over the Young Adult Life-Course}

Whereas the results presented in the previous section demonstrate the persistent influence of parental socio-economic status on family formation over time, another question is how persistent the influence of family background is over the lifecourse? Using results from the first study reported on above, Fig. 4.4 shows that the influence of parental education on the timing of entry into a union decreases as young adults age. At a young age (adolescence and the first years of young adulthood), the effect of parental education on timing of first marriage is particularly 


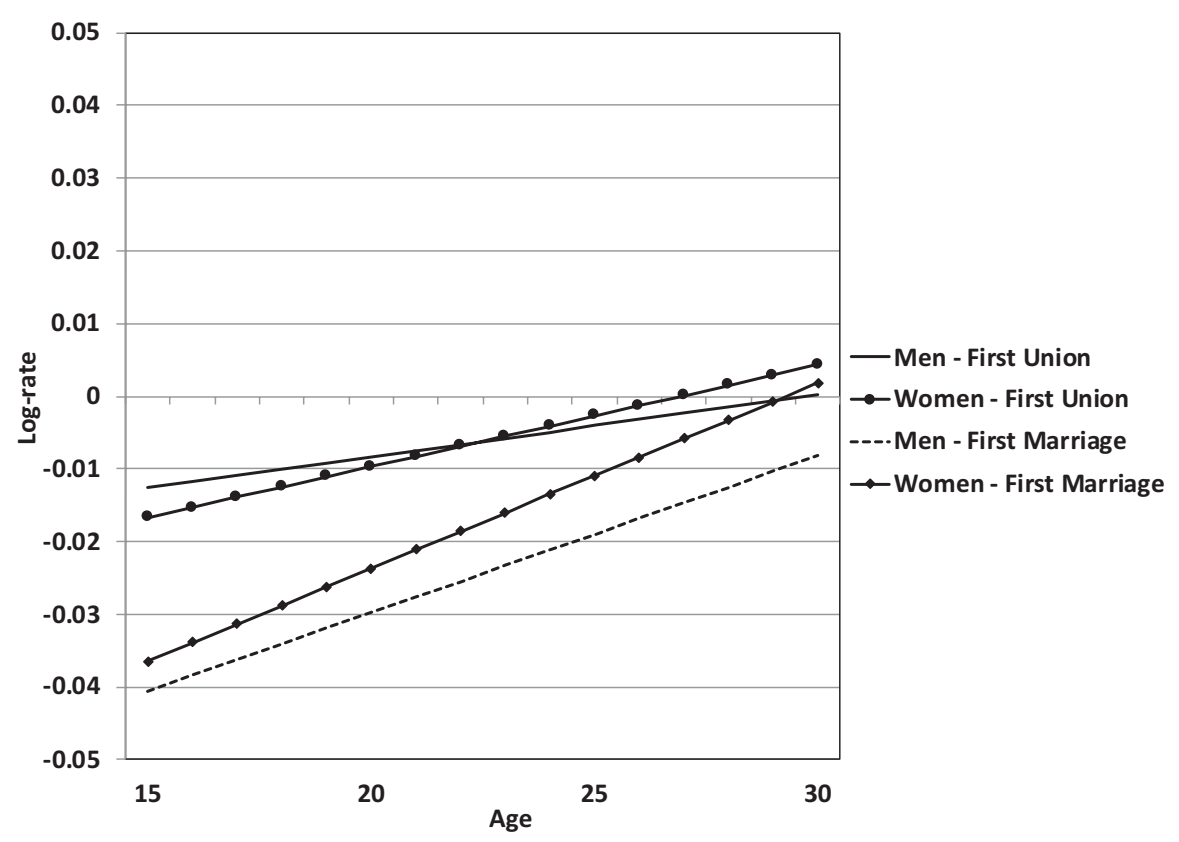

Fig. 4.4 Parameter estimates of the effect of parental education on first union and marriage rates by age

strong. Moreover, this effect is slightly stronger for men than for women. The graphs show that for both the timing of the first union and of the first marriage, the influence of parental education decreases as the young adults age and lose importance when they reach their late twenties. Other results from this study show that the influence of parental education on timing of first marriage decreases once someone enters a cohabiting union. These results show the relevance of the life-course perspective. The impact of parents is not constant, but is stronger at younger ages and the influence of parents decreases when the young adult enters a cohabiting relationship.

The results thus far covered the link between parental background and family formation and have shown that parental background is associated with different family formation pathways, but that the influence of parental background appears to decrease with age and as individuals enter transitions (such as entering a cohabiting relationship). Yet, what is unclear is what consequences these differences in lifecourse pathways between those from advantaged and disadvantaged background have on their socio-economic position. Also, the question is to what extent these socio-economic differences are a consequence of the different life-course pathways that young adults from advantaged and disadvantaged background follow or whether the influence of parental background on their socio-economic position reaches past young adulthood. In order to unravel this, one needs to consider another important aspect in the life-course, which is one's career. Career tracks can also can be better 
understood using a more holistic perspective. For instance, the school-to-work transition is better understood as a process than as a single transition (Brzinsky-Fay 2014). I therefore conducted a study, reported on in Mooyaart (2019) that examines the influence of family background and career and family pathways during the transition to adulthood (ages 17 to 25) on income trajectories in young adulthood (ages 25 to 32). This study examines the influence of career and family from a holistic life-course perspective, by distinguishing the different career and family pathways that young adults in the US typically follow and examining the impact that they pathways have income trajectories. Furthermore, this study assesses to what extent family background differences in income trajectories in young adulthood can be explained by these career and family pathways. In other words, can the differences in income trajectories between those of advantaged or disadvantaged background be explained by differences in the career and family pathways they follow or does the influence of family background reach further into young adulthood?

This study uses data from the National Longitudinal Survey of Youth of 1997 (NLSY97), an ongoing panel study conducted by the U.S. Bureau of Labor statistics, following the life courses of high school students in 1997 until well into young adulthood. With information on multiple aspects of family background such as parental income, parental educational level, childhood family structure and race, the multifaceted nature of family background influences could also be taken into account. A typology of the most typical career pathways was created and the same was done for family pathways, using hierarchical clustering and Optimal Matching (Abbott and Tsay 2000). Instead of including categorical cluster membership variables, I constructed continuous Grade of Membership (GoM) measures indicating the extent that someone's career and family pathways matches that of the most typical pathway of a particular career or family pathway cluster. The influence of both the family background indicators and the career and family GoM measures were estimated using growth curve modeling. More information on the methods can be found in my dissertation (Mooyaart 2019).

Results from this study show that the personal incomes of young adults depend both on their career pathway during young adulthood and on their family formation pathway. However, overall, their career pathway is a more important determinant of their personal income than their family formation pathway. In this chapter, however, I will focus on the impact of family background on income trajectories after taking into account differences in career and family pathways. The results of this study indicate that while the effect sizes of family background indicators decrease, many of them are still significant even when the career and family pathways are included. In order to visualize these differences, I will present the predicted incomes for a group with advantaged background characteristics and for a group with disadvantaged background characteristics. Advantaged is defined as coming from a white family with married parents from the top income quartile, with at least one parent with a 4-year college education. The Disadvantaged background is defined as the opposite, i.e. non-intact and non-white homes, lowest income quartile, with neither parent having more than high-school education. Figures 4.5 and 4.6 show these predicted income trajectories between ages 25 and 32 for the advantaged and 


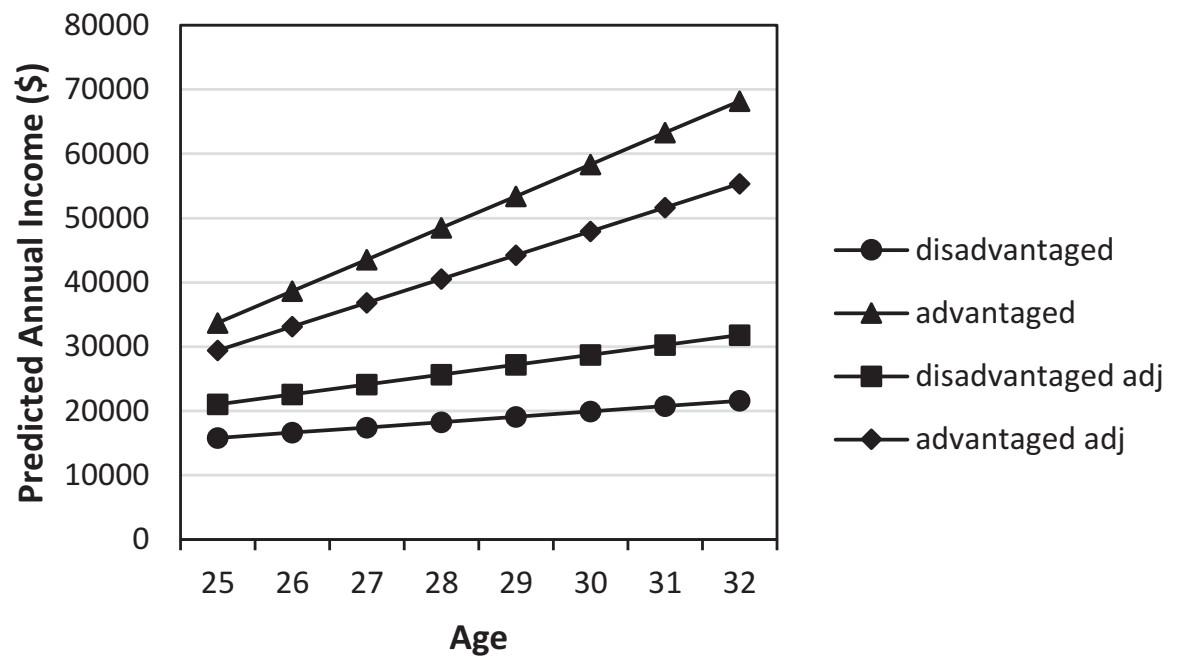

Fig. 4.5 Predicted income trajectories for men from "advantaged" and "disadvantaged" family backgrounds, with and without adjusting for pathways in young adulthood (GoM adjustment)

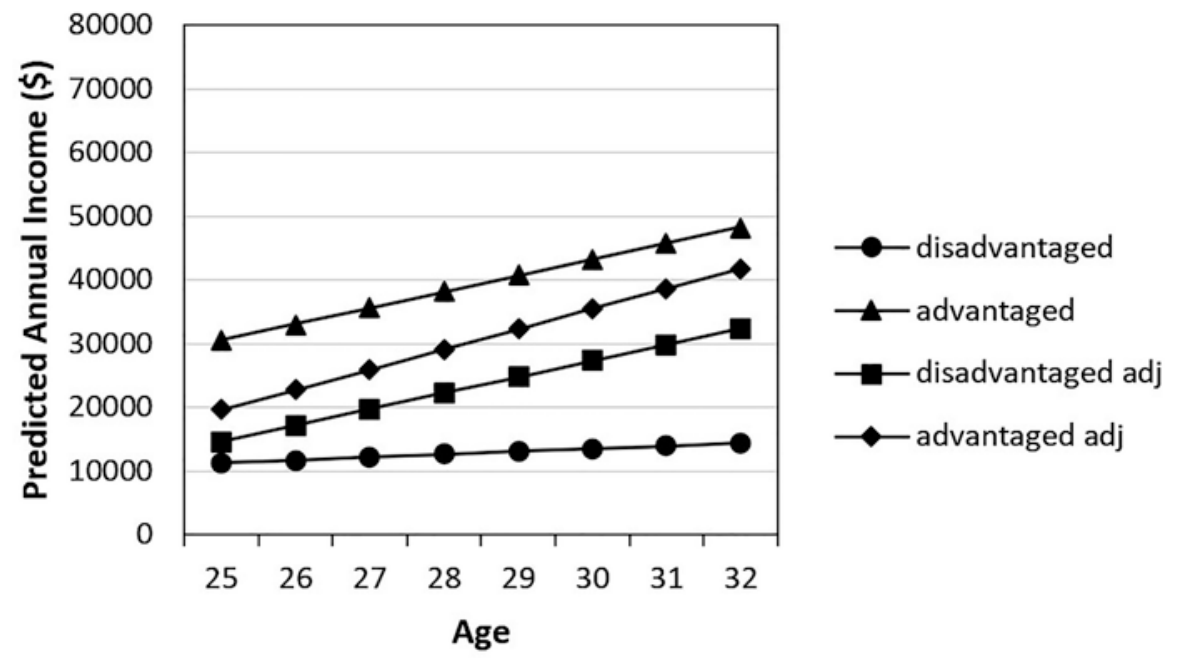

Fig. 4.6 Predicted income trajectories for women from "advantaged" and "disadvantaged" family backgrounds, with and without adjusting for pathways in young adulthood (GoM adjustment)

disadvantaged group, for men and women respectively. The figures display both the total difference between the two groups and how much difference would remain if one were to remove differences in career and family pathways that individuals follow (GoM adjusted).

In both figures, a large difference can be observed between the advantaged and disadvantaged group. Not only are there large income differences, the differences 
also become larger with age. For instance, in Fig. 4.5, the income for a man with an advantaged background is estimated to be around $\$ 35,000$ annually at age 25 , while this is around $\$ 15,000$ for a man from a disadvantaged background. At age 32, the man from an advantaged background is estimated to earn almost $\$ 70,000$, while the man from a disadvantaged background only earns around $\$ 22,000$ annually. Thus, a clear pattern of divergence is observed. However, this pattern of divergence is still observed (although somewhat reduced) when taking into account differences in the career and family pathways that individuals follow. At age 32, the estimated annual income for a man of an advantaged background is now around $\$ 55,000$, whereas a man from disadvantaged background earns about $\$ 32,000$. Thus, even after controlling for the career and family pathways up to age 25 , socio-economic background differences account for large income gaps between those from advantaged and disadvantaged background. Figure 4.6 shows that for women differences are somewhat smaller, particularly after taking into account the different career and family pathways that women follow. However, also for women there is a substantial remaining impact of socio-economic background. This indicates that family background does not only increase the likelihood of having a career and family pathway that is more associated with a higher income trajectory, but that regardless of one's career pathway, coming from a higher socio-economic background still boosts one's income.

\subsection{Conclusion and Discussion}

In this chapter, I examined the relationship between socio-economic background and family formation over time and over the (young) adult life-course and to what extent disadvantage persists in young adulthood. The first question that was posed in this chapter was about whether there has been any change in the relationship between socio-economic background and family formation over time. To answer this question, I used results from two studies in which I examined the union and family process in more detail and more holistically than was done in previous research. My results show that while family formation patterns have changed dramatically over time for individuals from all social backgrounds, socio-economic background continues to stratify family formation pathways. My results show that union and family formation behavior still varies strongly by the educational level of the parents. My results even suggest that differences between social classes in terms of family pathways have increased over time. These results run counter to the ideas of a choice biography (Giddens 1991; Woodman 2009) and SDT theory (Lesthaeghe 2010; Lesthaeghe and Van de Kaa 1986), which would have predicted an increasingly more equal diffusion of family formation behaviors across people of different social background. Instead, the results in this chapter appear to resonate with the findings of the Pattern of Disadvantage and Diverging Destinies literatures (McLanahan and Jacobsen 2015; Perelli-Harris et al. 2010). That is not to say that the SDT theory is of no merit, but rather that it needs to acknowledge the continuing divide between social classes in their family formation patterns. I would even argue 
that the cultural changes associated with the SDT, i.e. the acceptance of unmarried cohabitation, childbirth outside of marriage, and divorce, have created new pathways towards disadvantage, as pathways that include these behaviors are particularly common among young adults from low socio-economic backgrounds. Parents with high socio-economic status, on the other hand, are more successful in steering their children towards pathways that involve relative low risk, by letting them postpone more serious family commitments, such as marriage and childbearing.

The results of the studies in this chapter are in line with recent research by Brons et al. (2017) and Koops et al. (2017) who have demonstrated that in most European and North American countries parental education impacts the timing of first union and partnership context of first birth. While in these studies the effect of parental education became non-significant once accounted for the educational level of the individual, I argue that it is still important to continue to investigate the link between social background and family formation, since the way young adults form their families may be the bedrock for the transfer of advantage or disadvantage to their children. Furthermore, while enrollment in education may shape family formation patterns, it is also family formation patterns that shape educational attainment. Thus, highly educated parents may be more able to let their children become highly educated because they prevent their children from making family formation choices that entail strong commitments early in their young adult life-course. While both studies have demonstrated this continuing influence of socio-economic background on family formation, it would be important to continuously update these results with more recent information, and also from more different country contexts.

The second question posed in this chapter was a broader one focusing on how far the influence of socio-economic background reaches. The studies in this chapter suggest that while the influence decreases with age, socio-economic background continues to impact aspects related to family formation and the socio-economic position of young adults. I first showed some results on how the influence of parental education develops during young adulthood. I showed that, in the Netherlands, the negative effect of parental education on the timing of first union and first marriage is stronger at younger ages and more influential for the timing of first marriage than for the timing of the first union. In addition, the influence of parental education on marriage timing decreased substantially once young adults had entered a cohabiting union. This is in line with the idea that highly educated parents are more likely to support their children in following paths in which serious family commitments are postponed to ensure a good romantic match and a well-developed work career. Still, this comes with the side note that once a cohabiting partner is involved it is likely that the partner replaces the parents as the most important influence on marriage timing decisions.

Apart from the influence of socio-economic background on family formation, I also examined the influence of socio-economic background on personal income after taking into account different family and career pathways that individuals follow in their early to mid-twenties. With this study, I showed the benefits of applying a life-course perspective for the literature on the intergenerational transmission of (dis)advantage. Results showed that those who come from an advantaged social 
background still benefit from this background during young adulthood in that their personal income remains substantially higher than that of those from a disadvantaged background, and that these differences even in increase between ages 25 and 32 , particularly among men. This shows that socio-economic advantages stemming from the parental home not only help guide young adults taking the "right" paths in terms of career and family transitions, but help young adults even beyond these aspects to obtain advantaged social positions in life. In other words, the intergenerational transmission of advantage does not only run through education and family transitions. Potential mechanisms as to how socio-economic background would continue to impact income, could be the social networks that parents provide that help their children with acquiring (high-quality) jobs, or providing resources to help children move to locations where high paying jobs are to be found. Future research should uncover not only the mechanisms by which socio-economic background continues to influence the lives of young adults, but also examine whether socioeconomic background also continues to influence young adults in other aspects of life. Mooyaart et al. (2019) for instance found that social background has a weaker impact on obesity after taking into account career and family transitions in young adulthood, but that the impact of parental education on obesity still is far from negligible. This type of research should be extended to other outcomes such as mental health, substance use and criminal activity. Furthermore, my example on inequalities in income in this chapter only focused on the United States. Future studies should conduct comparative research both between country contexts and over time.

Research on the link between socio-economic background and family formation and on the intergenerational transmission of (dis)advantage could benefit from the growing number of longitudinal life-course studies that are being conducted. However, currently only a couple of countries have such extensive longitudinal surveys. Another approach could be to try to use information from the internet and social media as individuals leave a "digital footprint" of characteristics of their life courses. This information could then possibly be linked to survey or register data. Apart from getting the 'right' data, it is also important that our methodology is improved in order to better capture the meaning of the life course. My first example used the more classic approach of event-history analysis also including competing risks analysis. However, with event-history analysis one can only focus on a single transition. My second example, using CTA, shows that event-history analysis can be used in combination with sequence analysis, allowing one to examine the family process in its complexity (holistically). With respect to sequence analysis, the CTA approach allowed a clearer distinction between clusters as the variation on timing of the first family event was removed. My third example also used sequence analysis in an innovative way, by using Grade of Membership variables to indicate how close someone's career and family pathway is to a typical pathway, rather than simply using cluster categorical (dummy) variables. Not only did I find that these variables better predicted income differences compared with cluster dummy variables, but also that they are better at predicting income differences compared with models using simple indicators such as level of education and marital status. These examples have shown possible directions for future research on life-course to further explore. 
All and all, results in this chapter have shown that the influence of socio-economic background on family formation is persistent over time and that the impact of socioeconomic background reaches far into young adulthood, across multiple country contexts. Yet, more research with a life-course perspective is needed to improve our understanding further on how social inequality persists.

Acknowledgements The research leading to these results has received funding from the European Research Council under the European Union's Seventh Framework Programme (FP/2007-2013)/ ERC Grant Agreement n. 324178.

\section{References}

Aassve, A., F.C. Billari, and R. Piccarreta. 2007. Strings of adulthood: A sequence analysis of young British women's work-family trajectories. European Journal of Population 23 (3-4): 369-388.

Abbott, A., and A. Tsay. 2000. Sequence analysis and optimal matching methods in sociology: Review and prospect. Sociological Methods \& Research 29 (1): 3-33.

Avery, R., F. Goldscheider, and A. Speare. 1992. Feathered nest/gilded cage: Parental income and leaving home in the transition to adulthood. Demography 29 (3): 375-388.

Axinn, W.G., and A. Thornton. 1992. The influence of parental resources on the timing of the transition to marriage. Social Science Research 21 (3): 261-285.

Blau, P.M., and O.D. Duncan. 1967. The American occupational structure. New York: Free Press.

Blossfeld, H.-P., and Y. Shavit. 1993. Persisting barriers: Changes in educational opportunities in thirteen countries. In Persistent inequality: Changing educational attainment in thirteen countries, ed. Y. Shavit and H.-P. Blossfeld, 1-23. Boulder: Westview Press.

Breen, R., and J.H. Goldthorpe. 1997. Explaining educational differentials: Towards a formal rational action theory. Rationality and Society 9 (3): 275-305.

Brons, M.D., A.C. Liefbroer, and H.B.G. Ganzeboom. 2017. Parental socio-economic status and first union formation: Can European variation be explained by the Second Demographic Transition theory? European Sociological Review 33 (6): 809-822.

Brückner, H., and K.U. Mayer. 2004. De-standardization of the life course: What it might mean? And if it means anything, whether it actually took place? Advances in Life Course Research 9: 27-53.

Brzinsky-Fay, C. 2014. The measurement of school-to-work transitions as processes. European Societies 16 (2): 213232.

Buchmann, M.C., and I. Kriesi. 2011. Transition to adulthood in Europe. Annual Review of Sociology 37 (1): 481-503.

Cavanagh, S.E. 2011. Early pubertal timing and the union formation behaviors of young women. Social Forces 89 (4): 1217-1238.

Easterlin, R.A. 1980. Birth and fortune: The effects of numbers on personal welfare. New York: Basic Books.

Elder, G.H., Jr. 1994. Time, human agency, and social change: Perspectives on the life course. Social Psychology Quarterly 57 (1): 4-15.

Elzinga, C.H., and A.C. Liefbroer. 2007. De-standardization of family-life trajectories of young adults: A cross-national comparison using sequence analysis. European Journal of Population 23 (3-4): 225-250.

Giddens, A. 1991. Modernity and self-identity. Self and society in the modern age. Cambridge: Polity Press. 
Kiernan, K. 2004. Unmarried cohabitation and parenthood in Britain and Europe. Law \& Policy 26 (1): 33-35.

Koops, J.C., A.C. Liefbroer, and A.H. Gauthier. 2017. The influence of parental educational attainment on the partnership context at first birth in 16 Western societies. European Journal of Population 33 (4): 533-557.

Lesthaeghe, R. 2010. The unfolding story of the Second Demographic Transition. Population and Development Review 36 (2): 211-251.

Lesthaeghe, R., and D.J. Van de Kaa. 1986. Twee demografische transities, 9-24. Groei En Krimp: Bevolking.

Mclanahan, S. 2004. Diverging destinies: How children are faring under the Second Demographic Transition. Demography 41 (4): 607-627.

McLanahan, S., and W. Jacobsen. 2015. Diverging destinies revisited. In Families in an era of increasing inequality, ed. P.R. Amato, A. Booth, S.M. McHale, and J. Van Hook, 3-23. New York: Springer.

Mooyaart, J.E. 2019. Linkages between family background, family formation and disadvantage in young adulthood (Doctoral dissertation, Rijksuniversiteit Groningen).

Mooyaart, J.E., and A.C. Liefbroer. 2016. The influence of parental education on timing and type of union formation: Changes over the life course and over time in the Netherlands. Demography 53 (4): 885-919.

Mooyaart, J.E., A.C. Liefbroer, and F.C. Billari. 2019. Becoming obese in young adulthood: The role of career-family pathways in the transition to adulthood for men and women. BMC Public Health 19 (1511) 12pp.

Mulder, C.H., W.A.V. Clark, and M. Wagner. 2006. Resources, living arrangements and first union formation in the United States, the Netherlands and West Germany. European Journal of Population 22 (1): 3-35.

Perelli-Harris, B., and T.P. Gerber. 2011. Nonmarital childbearing in Russia: Second demographic transition or pattern of disadvantage? Demography 48 (1): 317-342.

Perelli-Harris, B., W. Sigle-Rushton, M. Kreyenfeld, T. Lappegård, R. Keizer, and C. Berghammer. 2010. The educational gradient of childbearing within cohabitation in Europe. Population and Development Review 36 (4): 775-801.

Shanahan, M.J. 2000. Pathways to adulthood in changing societies: Variability and mechanisms in life course perspective. Annual Review of Sociology 26 (1): 667-692.

South, S.J. 2001. The variable effects of family background on the timing of first marriage: United States, 1969-1993. Social Science Research 30 (4): 606-626.

Studer, M., A.C. Liefbroer, and J.E. Mooyaart. 2018. Understanding trends in family formation trajectories: An application of Competing Trajectories Analysis (CTA). Advances in Life Course Research 36: 1-12.

Thornton, A. 1991. Influence of the marital history of parents on the marital and cohabitational experiences of children. American Journal of Sociology 96 (4): 868-894.

Thornton, A., W.G. Axinn, and J.D. Teachman. 1995. The influence of school enrollment and accumulation on cohabitation and marriage in early adulthood. American Sociological Review 60 (5): 762-774.

Wiik, K.A. 2009. 'You'd better wait!' - Socio-economic background and timing of first marriage versus first cohabitation. European Sociological Review 25 (2): 139-153.

Woodman, D. 2009. The mysterious case of the pervasive choice biography: Ulrich Beck, structure/agency, and the middling state of theory in the sociology of youth. Journal of Youth Studies 12 (3): $243-256$.

Zimmermann, O., and D. Konietzka. 2017. Social disparities in destandardization-Changing family life course patterns in seven European Countries. European Sociological Review 34 (1): 64-78. 
Open Access This chapter is licensed under the terms of the Creative Commons Attribution 4.0 International License (http://creativecommons.org/licenses/by/4.0/), which permits use, sharing, adaptation, distribution and reproduction in any medium or format, as long as you give appropriate credit to the original author(s) and the source, provide a link to the Creative Commons license and indicate if changes were made.

The images or other third party material in this chapter are included in the chapter's Creative Commons license, unless indicated otherwise in a credit line to the material. If material is not included in the chapter's Creative Commons license and your intended use is not permitted by statutory regulation or exceeds the permitted use, you will need to obtain permission directly from the copyright holder. 